\title{
REGIONAL VERSUS INTER-REGIONAL EFFICIENCY IN RESOURCE ALLOCATIONS
}

\author{
Gunter Schramm ${ }^{1}$
}

\section{INTRODUCTION}

This discussion investigates the question whether the introduction of compensation payments for resource transfers between independent regions with unequal endowments of resources such as water would lead to an efficient inter-regional allocation and utilization pattern of these resources.

The basic assumption underlying the analysis is that the respective regions have either complete or partial jurisdiction or ownership rights over these resources so that they themselves could determine or at least substantially influence existing and future utilization patterns. Given this criteria, the definition "region" would mean a special political subunit such as an individual water district, it could mean an individual state or province forming part of a larger national unit, or it could refer to a sovereign country such as Canada or the United States.

Regional efficiency, then, can be defined as the maximization of net benefits accruing to the region itself from the utilization of the particular resource within or without its own boundaries, whereas inter-regional efficiency refers to the maximization of total net benefits for all affected regions combined. The analysis will be conducted in terms of usual benefitcost terminology, with net benefits referring to the present value of the sum of public and private total benefits minus the sum of public and private total costs. However, such a definition raises three important issues.

The first is the question of the appropriate rate or rates of discount, a question which has found much attention in the literature without resulting in a

${ }^{1}$ The author is Associate Professor of Resource Economics at the University of Michigan, School of Natural Resources.

In developing this paper I have benefitted from comments by the late Ayers Brinser, P. S. Dhruvarajan, Charles W. Howe, Saul H. Hymans and Gail R. Wilensky. Needless to say, the responsibility for the analysis and the conclusion drawn is entirely my own.

The research underlying this paper was supported by a grant of the Canadian Department of Energy, Mines and Resources. 
final consensus. ${ }^{2}$ In this paper the problem will be disregarded on the assumption that an appropriate rate has been found.

The second is the problem of the relevant opportunity costs of foregone alternatives. It will be shown that the range and magnitude of these opportunity costs are different for different regions, with the result that the sum of efficiency solutions of individual regions will not necessarily be equal to the optimum inter-regional efficiency solution. ${ }^{3}$ This issue is at the heart of the analysis presented here.

The third issue is the problem of defining the relevant regional or interregional benefits as such. Standard benefit-cost analysis defines net benefits as the excess of the value of project outputs (whether they are marketed or not) over project costs, a definition which is akin to the definition of profits in the private sector. However, it must be assumed that the objective of a regional government or authority ought to be the maximization of net benefits for the population under its jurisdiction as a whole. This means that total net benefits should include the net addition to factor incomes ${ }^{4}$ or personal well-being ${ }^{5}$ of the region's population. In other words, the true net benefits are the increases in total real monetary and non-monetary net value added accruing to the

${ }^{2}$ For some recent discussions presenting divergent views see, for example; Committee on The Economics of Water Resources Development of The Western Agricultural Economics Research Council, Water Resources and Economic Development of the West, The Discount Rate in Public Investment Evaluation, Denver, Col. Dec. 17-18, 1968; Peter O. Steiner, Public Expenditure Budgeting, The Brookings Institution, Washington, 1969; W. J. Baumol, "On the Social Rate of Discount," American Economic Review, Sept. 1968 (see also the six comments on Baumol's paper inthe same Journal, Dec. 1969), Gunter Schramm, "The Design of a Resource Allocation Function, "paper presented to the 3rd Annual Meeting of the Canadian Economics Association, Toronto, June 1969 , mimeo.

$3^{3}$ It should be noted that inter-regional efficiency does not necessarily mean national, inter-national or global efficiency. A water-transfer scheme between the Pacific Northwestern states and Arkansas, for example, will likely have an inter-regional efficiency solution that will differ from that for the United States as a whole. In the analysis presented here inter-regional efficiency refers exclusively to the maximization of net benefits for the affected regions.

${ }^{4}$ The emphasis is on the word "net addition." For example, if as a result of a specific resource allocation policy the income of certain individuals increases from, say $\$ 3.00$ to $\$ 3.50$ per hour, the net benefit is $\$ 0.50$ per hour minus the increase (or change) that would have taken place in the absence of this policy.

5 These might be environmental, "quality of life," recreational or other nonmarketed benefits. 
region. ${ }^{6}$ While such a definition of benefits is conceptually more acceptable than the narrower one of usual benefit-cost analysis, data and analytical problems will generally make it exceedingly difficult if not impossible to establish their magnitude. ${ }^{7}$ It is not possible within the framework of this paper to pursue this issue further. However, it is an issue of great importance that requires much more attention than it has received in the past. ${ }^{8}$

II

\section{THE NEED FOR COMPENSATION PAYMENTS}

Having presented these caveats let us now turn to the central question under discussion here: will the introduction of explicit compensation payments to a resource-owning region result in an efficient inter-regional allocation of this resource between regions? This question is particularly important for the allocation of water resources. In recent years many proposals have been made for the massive transfer of water from so-called "water-rich" to "waterdeficient" regions. ${ }^{9}$ Ranging from the proposed huge, but still relatively

${ }^{6}$ The evaluation has to be conducted in real rather than monetary terms because of the possibility of price changes resulting from the policy adapted.

${ }^{7}$ In addition, there exist very real problems of defining the relevant range of beneficiaries over time, particularly if the problem of regional in- or outmigration is taken into consideration.

${ }^{8}$ U. S. Federal Water Resources Agencies have recognized this problem and are presently trying to find a solution. See the Report by the Special Task Force, United States Water Resources Council, Procedures for Evaluation of Water and Related Land Resource Projects, Washington, D. C. June 1969 .

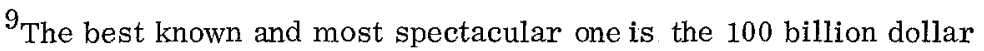
NAWAPA scheme of the Ralph M. Parsons Company which suggests the diversion of so-called "surplus" water from Alaska, the Yukon, British Columbia and other northern areas to regions as far east as Quebec and as far south as Mexico. This proposal has been strongly supported by Senator Frank E. Moss. It has also found qualified support in a special U. S. Senate study. For the proposal itself and the supporting views see: Ralph M. Parsons Company, NAWAPA, North American Water and Power Alliance, Brochure 606-2934-19, Los Angeles, Calif., 1965; Ralph M. Parson Company, North American Water and Power Alliance, Conceptual Study, Vol. II, Financial, Los Angeles, Jan. 1966; Frank E. Moss, The Water Crisis, Frederick A. Praeger, Inc., New York, 1967; and Committee on Public Works, U. S. Senate, Western Water Development, 88th Congress, 2nd Session, Wash., D. C., October 1964.

A modification of this proposal which attempts to eliminate British Columbia's objection against the proposed flooding of the Rocky Mountain 
"modest" Columbia-Colorado transfer of 2.4 million acre-feet per year which would cost something like $\$ 1.4$ billion dollars, to the mammoth 110 million acre-feet per year, $\$ 100$ billion dollar NAWAPA scheme, none of these proposals have taken into account that the present, resource-owning states and provinces have a very legitimate, long-term interest in retaining the flows of these rivers for their own, future use. ${ }^{10}$

As a result, all of these proposals provoked a swift and hostile reaction in the jurisdictions from which the water was to be diverted. ${ }^{11}$ The NAWAPA

Trench was developed by Lewis Gordon Smith. See his Western States Water Augmentation Concept, Federation of Rocky Mountain States, Inc., Denver, Col., revised ed. 1968 .

An internal United States transfer of Snake River waters to the lower Colorado has been under discussion for quite some time. For a brief description of the project see: Los Angeles Department of Water and Power, The Snake-Colorado Project, Los Angeles, undated.

Another proposal visualizes the diversion to the Great Lakes of various rivers flowing into St. James Bay. For a discussion see: Thomas W. Kierans, Great Replenishment and Northern Development Canal, Sudbury, Ont. Nov. 1964; T. W. Kierans, Stabilization of Great Lakes Levels and Flows by the Great Replenishment and Northern Development Canal, Presentation to the International Joint Commiss ion, May 1965; and T. W. Kierans, "The Great Replenishment and Northern Development Canal," Presentation to the Canadian Electrical Association, Manoir Richelieu, Murray Bay, Quebec, June 28, 1965.

A third group of diversion schemes investigates the potential of the northern Canadian Watersheds of the Nelson, Churchill and Athabaska Rivers as sources of additional water supplies to the Canadian Prairie Provinces and the mid-western United States. For a discussion see Edward Kuiper, "Canadian Water Export," The Engineering Journal, July 1966; E. Kuiper, "Water Utiliza:ion in Canada," Engineering Digest, June 1967; and E. Kuiper, "Feasibility of Water Export," Journal of the Hydraulics Division, Proceedings of the American Society of Civil Engineers, July 1968.

${ }^{10}$ The notable exceptions are the papers by E. Kuiper, ibid., which specifically propose compensation payments for "resource value" to the waterowing regions.

11

The following discussion should not be interpreted to mean that largescale water diversions are likely to provide the most efficient solutions to water supply problems in the various water-short areas of this Continent. As many observers have pointed out, a more intensive utilization of existing local supplies brought about by improvements in existing allocation procedures may well represent lower-cost solutions. Such measures may consist of a greater utilization of existing groundwater supplies, a minor shift from low-value agricultural to high-value industrial or municipal water use, intensified pollution control measures, sea or brakish water desalinization, improved techniques in 
scheme was greeted in Canada by outcries such as "Water Sharing Called Plunder. "12 The strong stand of the Columbia Basin states against the construction of the Grand Canyon Dams was in part the result of their fear that these dams would pave the way for an eventual transfer of Snake or Columbia River waters into the Colorado River system. ${ }^{13}$ The reason for this hostility is easy to see. From the point of view of water-parched Arizona, for example, much of the massive flows in the Columbia system may look like "surpluswater." From the point of view of the Pacific Northwestern States, however, no such surplus exists. Large flows of water can be used for many purposes. They can be used to turn hydraulic turbines or to dilute waste waters from industries or urban communities. They can be left in their original state to facilitate the passage of migratory fish or simply for the admiration of visitors and tourists. When the late General McNaughton, one of the most outspoken critics of Canadian water transfers to the United States claimed that, "... there is Never too much water"14 he certainly was right to a certain degree. Only in those rare cases where recurring floods threaten or where undrained marshes reduce the value of land can we speak of "surplus" water. In almost all others water will have a positive value, even if this value, on a per acre-foot basis, is very low indeed.

One of the important flaws of our inter-personal as well as inter-regional water allocation procedures is that these allocations are often made on the basis of "need." In any arbitration procedure, whether government or court determined, the party that can prove a greater "need" for water is likely to end up with a larger share of the limited supply. But the "needs" for water in physical terms are almost limitless. A Pacific Northwestern newsprint mill, for example, is reported to use process water in excess of 75,000 gallons per ton of product whereas similar mills in the Southern United States (in areas which are far from water short) make do with less than 11, 000 gallons per

weather modifications and so on. For a discussion of these views see, for example: W. R. Derrick Sewell, "A Continental Water Supply System: Pipedream or Practical Possibility?", Bulletin of the Atomic Scientists, Vol. XXIII, No. 7, Sept. 1967, William A. Martin and Robert A. Young, "The Need for Additional Water in the Arid Southwest: an Economist's Dissent, "The Annals of Regional Science, Vol. III, No. 1, June 1969; Charles W. Howe, "Economics of Large-Scale Transfers," in William G. McGinnies and Bram J. Goldman, Arid Lands in Perspective, The University of Arizona Press, Tucson, Arizona, 1969 .

12 The Globe and Mail, Toronto, May 28, 1965.

13 For example, the former Secretary of the Interior Stewart Udall once referred to the Hualapai Dam (one of the two proposed Grand Canyon Dams) as "a gun pointed at the Columbia." From U.S. Congress, Senate, Committee on Interior and Insular Affairs, Central Arizona Project, Hearings before Subcommittee, 90th Congress, 1st session, May, 2-5, 1967, p. 162.

${ }^{14}$ As quoted in Engineering and Contract Record, November, 1965. 
ton 14 Even the best-endowed provinces or states on this Continent will have little difficulties to show that they could use more, rather than less water. 16 Given the uncertainties of future demands a regional government would indeed be derelict in its duties to its citizens if it voluntarily and without receiving compensation gave up any claim to water that forms part of the original resource endowment of its territory.

One of the results of resource allocations on the basis of "need" is that in cases where several jurisdiction jointly share streams or watersheds the individual demand projections of the various riparians will be grossly inflated. Who, after all, is going to say whether land that is marginal today may not be suitable for irrigation tomorrow ${ }^{17}$ The other result is that water diversions from one basin to another will be strenuously resisted by the original owner, even if it is quite apparent that the value of the water in its original location is much less than along the proposed diversion route.

The explicit introduction of compensation payments into negotiations about inter-regional water allocations could greatly help to establish a more realistic evaluation of regional water needs. 18 If the alternative to an inflated claim to water is not simply the loss of this water to somebody else but a claim to a potential source of future ' revenue it is much more likely that a regional government will try to assess realistically, and in terms of actually foregone

${ }^{15}$ Rolf Eiliassen, The Economics of Water in the Pulp and Paper Industry, unpublished manuscript, Engineering-Economic Planning Program. Stanford University, Stanford, Calif., mimeo, pp. 78-79.

${ }^{16}$ For example, in a discussion of proposed diversion schemes, A. F. Paget, British Columbia's former Deputy Minister of Water Resources asserted: "it seems that we desperately need to reserve all of our water resource potential. -- It is, therefore, very difficult for us to consider any reduction in the total volume of the resources we now possess. It is certain, that any such reduction would, in many areas, immediately reduce our economic advantage and could have a most serious and even destructive influence upon our resource management." From: A. F. Paget, British Columbia's Water Resource Potential, an address to the 53rd General Meeting, Pacific Northwest Trade Association, Portland, Oregon, April 11-13, 1965, p. 9.

${ }^{17}$ Unfortunately, the misallocation of resources does not stop with inflated demand projections. Most government agencies, regional as well as federal, have a tendency to accept these projections as real and to make investment decisions on their basis. The sad history of inflated demand projections for South Saskatchewan River irrigation water requirements stored behind the South Saskatchewan Dam in Canada is a case in point.

${ }^{18}$ Implicitly, of course, compensation payments in the form of tradeoffs, compromises, or $\log$-rolling processes and side-payments at the state and federal level are common enough. 
opportunity costs, the need for future water supplies.

The first step needed for the introduction of such compensatory payments would be to find some mechanistic allocation formula that would determine the rights to water for the riparian states bordering a common watershed. It might be agreed, for example, that a downstream state has title to fifty per cent of the average streamflow at the border crossing point. 19 In cases of outright diversions, of course, such distribution formulas would not be needed since title to the diverted waters would rest with the original owner. ${ }^{20}$ If one of the riparians would like to get a larger share of a common watershed or if he would like to divert some water from another jurisdiction he would have to offer to pay for it. If the offered compensation were to be higher than the marginal value of the water to its original owner arrangements of such transfers could follow. If it were to be less, no such transfers would take place. The likely result would be that existing water supplies would be allocated to those areas where their expected net marginal values are highest. It is useful to investigate this assertion in a more rigorous fashion in order to see whether it is likely to hold.

THE EFFECTS OF COMPENSATION PAYMENTS ON INTERREGIONAL RESOURCE ALLOCATIONS: THE STANDARD CASE

The question is: Would the explicit introduction of inter-state compensation payments lead to an efficient allocation of transferable natural resources?

At first sight the answer appears to be: yes, indeed it would. The

19

Such a rule sounds much simpler than it would be in reality. Rights to water would have to be established not only in quantitative, but also in qualitative terms. Agreements would invariably be very complex because of natural flow variations and permanent changes brought about by streamflow regulations and other man-made changes of water quantity and quality. Interestingly enough, a $50 \%$ sharing formula forms the basis of the otherwise more complex Alberta-Saskatchewan-Manitoba streamflow apportionment agreement for major inter-provincial streams which was signed in Regina on October 30 , 1969. See also, The Financial Post, Toronto, Nov. 15, 1969, p. 11.

${ }^{20}$ However, in some cases diversions might affect third parties farther downstream. These would have to be included in any sales agreement if their apportioned share of the existing streamflow would be affected. 


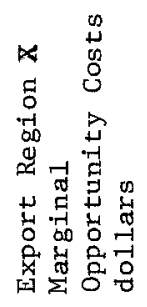

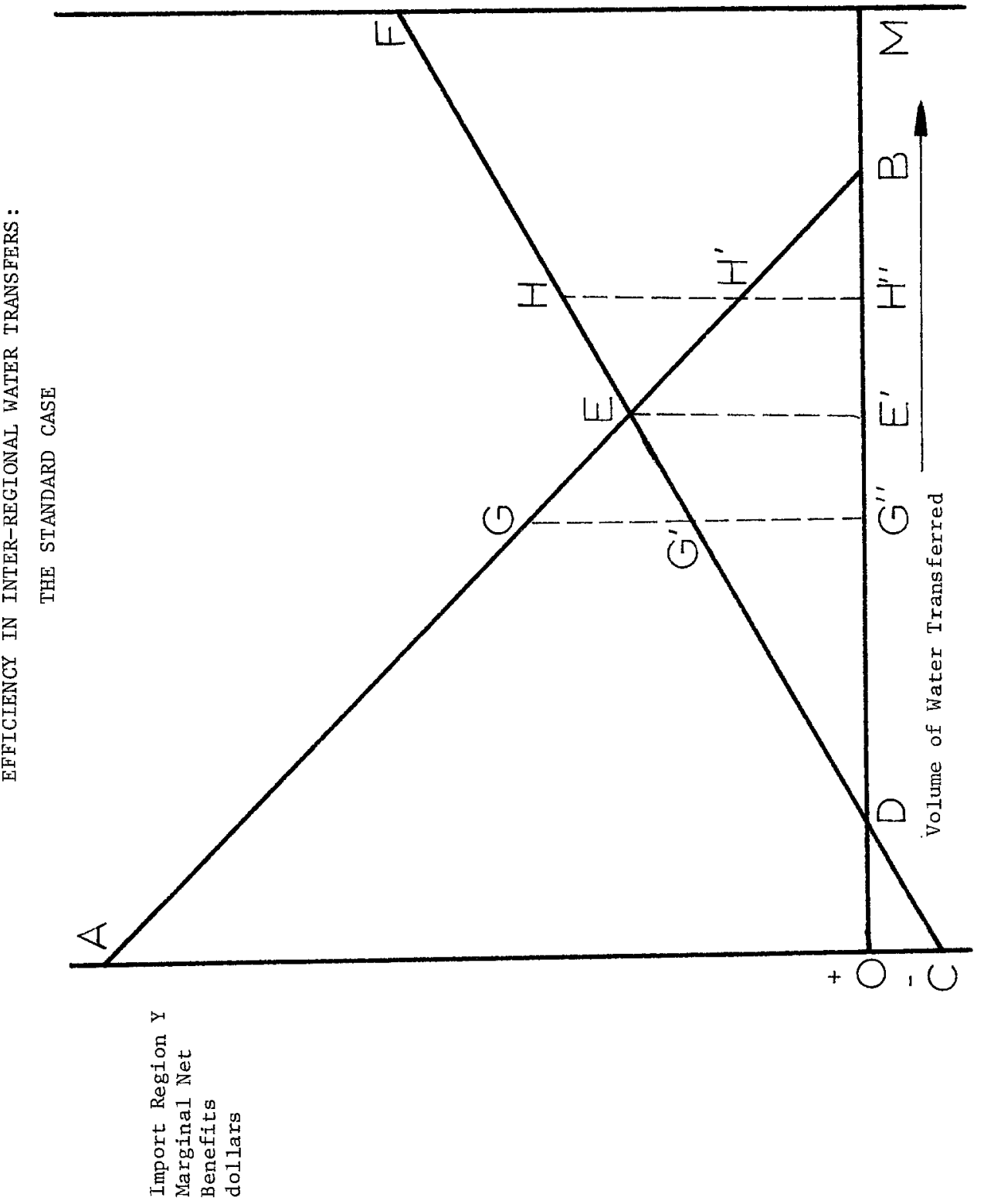


rationale of this answer is shown in figure $1 .^{21} \mathrm{X}$ and $\mathrm{Y}$ are two independent regions (Provinces, states) with jurisdiction over their own water resources. $\mathrm{X}$ owns large supplies whereas $\mathrm{Y}$ faces shortages. $\mathrm{OM}$ is the maximum quantity of water (in annual flow) that could be transferred from X to Y provided an agreement is reached.

The marginal net-benefits to region $Y$ from increasing water transfers from $X$ are given by $A E B$, whereas the marginal benefits to $X$ from utilizing the water within its own jurisdiction are given by FEDC. Between D and $O$ the yield of water to $\mathrm{X}$ is negative (flood damage?). FEDC, therefore, represents the reservation price of $X$. Between $D$ and $C$ this reservation price is actually negative, i.e. it would be rational for $\mathrm{X}$ to pay $\mathrm{Y}$ for removing this excess water. Clearly, $\mathrm{X}$ can be made better off by selling some of its water to $Y$ provided $Y$ is willing to pay $X ' s$ reservation price plus some of its own net benefits.

What will the optimal distribution be? A trade of $\mathrm{OH}^{\prime \prime}$ of water is inefficient since the loss to $\mathrm{X}$ of the marginal unit is $\mathrm{HH}^{\prime \prime}$ and the gain to $\mathrm{Y}$ is only $\mathrm{H}^{\prime} \mathrm{H}^{\prime \prime}$. If $\mathrm{OG}$ " of water is transferred the value of the marginal unit to $\mathrm{X}$ is $G^{\prime} G^{\prime \prime}$, whereas to $Y$ it is GG". In this case both parties could be made better off by trading additional quantities of water. The optimum is reached at $\mathrm{OE}^{\prime}$ where the marginal net benefits $\mathrm{EE}^{\prime}$ are equal to both parties. The minimum prices which $\mathrm{X}$ would charge for successive units of water are given by CDEF. To the right of $\mathrm{E}$, region's $\mathrm{X}$ reservation prices EHF are higher than the net gains to $\mathrm{Y}$ (given by $\mathrm{EH}^{\prime} \mathrm{B}$ ). Area $\mathrm{CAED}$ represents the total net gain available

21 It should be noted that the diagram shows net benefits only. This means that gross benefits have to be large enough to cover all water transportation costs in addition to the net benefits shown.

The analysis is formulated in terms of net regional and inter-regional benefits expressed in dollar terms. This assumes that the underlying welfare functions are also expressed in dollars so that they can simply be added together in order to find total inter-regional welfare, i. e. $\mathrm{W}_{\mathrm{T}}=\mathrm{U}_{\mathrm{X}}(\mathrm{q})+\mathrm{U}_{\mathrm{Y}}(\mathrm{Q}-$ q) where $W_{T}$ is total inter-regional welfare $Q$ is the total quantity of water available for possible transfer and $U_{X}$ and $U_{Y}$ are the respective welfare functions of regions $\mathrm{X}$ and $\mathrm{Y}$. While this assumption is convenient for the graphical representation of the analysis it is not really necessary for the conclusions to hold. If part or all of the presumed welfare generated in a region is greater (or less) than the amount of dollar benefits shown the function could be weighted by a special welfare coefficient. This would change and/or shift the marginal net benefit curve of the particular region and benefits would no longer be expressed in dollars but in terms of the weighted welfare function. However, such a weighting scheme, while it would still indicate the likely equilibrium trading position between $\mathrm{X}$ and $\mathrm{Y}$ may no longer represent the most efficient solution from an inter-regional government point of view (the Federal Government's, for example) if this government holds a different view of the appropriate welfare weighting scheme. 
to both $\mathrm{X}$ and $\mathrm{Y}$ from the optimal water transfer OE'. How this gain will be distributed between the two regions will depend on the bargaining power and skill of the two parties. But whatever this distribution it appears that in terms of overall. efficiency a water transfer of $\mathrm{OE}^{\prime}$ will maximize total net benefits and it also appears that the self-interest of both regions will lead to just such a transfer.

IV

\section{BENEFIT DISTRIBUTIONS AND THEIR EFFECT ON COMPENSATION PAYMENTS}

Unfortunately, it can be shown that the conclusion arrived at in the preceding section does not necessarily follow. It follows only in cases where the evaluation of net benefits does not involve the private sector and separate jurisdictions. Most of our resources, and water is no exception, are utilized in the private rather than the public sector. Why do private firms use resources? They do so because they expect it to be profitable. A dryland farmer will switch to irrigation farming only if he expects that his income will increase. A pulpmill, a power company will utilize water only if it is profitable to do so. What this means is that part, and most likely a very large part, of the benefits accruing to a region from a resource transfer will be private benefits of the firms and enterprises that are going to use them. Total regional net benefits, therefore, will consist of the sum of net public and net private benefits. But private activities can be attracted to a region only if a minimum profit expectation is met. If it is not, the activity will not take place and the resources made available will not be used.

This has certain consequences for the evaluation of regional net benefits because regional economics are largely open economics. To attract new activities and new firms the region must offer rates of return that are competitive with rates obtainable elsewhere. Furthermore, the smaller or more open a regional economy is the more likely it is that the opportunity costs of new private investments to the region are zero.

Since this is the crucial point of the analysis that follows let us elaborate further. If we were to assume, for example, that the relevant region for the analysis would be the United States as a whole and that the United States would represent a closed economic system with no possible net capital inflows or outflows, then, given a full-employment situation, any new investment in any subregion of the country would preclude some other investment of similar magnitude elsewhere. From the national point of view, therefore, the net benefits of any individual investment in any subregion would have to be calculated net of the foregone opportunity costs that the funds invested therein could have earned elsewhere. However, this conclusion does not hold at the sub-national, or regional level. Let us assume, for example, that the State of Arizona is considering the relevant benefits and costs of water imports for an expansion of irrigated agriculture. Let us assume further that the land to be irrigated could otherwise be used only for low-density cattle pastures (or not be used at 
all). With additional water supplies, the landowners could raise sufficient funds elsewhere (say, in the New York money market) to convert their holdings into irrigated agricultural land. Considering only the economic dimensions of this problem ${ }^{22}$ they are likely to do so if such conversion meets their minimum profit expectations net of the costs of funds they have to invest. But these minimum expected profits must be considered net benefits from Arizona's point of view, ${ }^{23}$ while, as we have seen before, they cancel out from the national point of view. In other words, from Arizona's point of view the opportunity costs of funds attracted to Arizona from outside the State are zero. ${ }^{24}$

It is the necessity to meet the minimum profit expectation of the private, water-induced sector of the regional economy together with the fact that the regional opportunity costs of funds may, in many cases, be zero or close to zero which modifies the findings of our previous analysis. Let us illustrate.

The interpretation of figure 2 parallels that of figure 1 . However, we now have shown the minimum profit expectation of private enterpreneurs or corporations by distance JO or $\mathrm{FF}^{\prime}$ respectively. To simplify the analys is we have assumed that this minimum is constant per unit of water utilized. If this rate of return (or, in terms of figure 2, the minimum net benefits as indicated by JO) cannot be obtained the private activity will not take place. This, from a national point of view would not matter since by assumption these minimum private net benefits represent their opportunity costs of being generated somewhere else in the economy. As a matter of fact, these benefits represent a classical case of secondary benefits which, from a national point of view cancel out. 25 They do not cancel out, however, for the independent regions either

\section{${ }^{22}$ Which leaves out the important issues of perception, attitudinal} changes, training and willingness to take risks.

${ }^{23}$ In addition, increases in the net income of farm laborers, farm suppliers and farm products processors as well as net increases in local and state governmental revenue (net of additional required expenditures) should also be included. I. e., as has been pointed out before, the appropriate measure would be the net increase in value added accruing to Arizona as a whole. However, if the water importation policy also results in significant population in-migration into Arizona a more appropriate measure would be the net increase in value added per capita.

${ }^{24}$ What must be deducted, however, are the net benefits from land utilization (cattle raising?) that would accrue in the absence of irrigation.

25 Only in cases where the resources used (i.e. the capital and labor) would remain idle if not invested in the water-import-induced activity would it be legitimate to include them as net benefits in the national benefit function. For a discussion of secondary benefits see, for example: Julius Margolis, "Secondary Benefits, External Economics and the Justification of Public Investments," Review of Economics and Statistics, August 1957. 


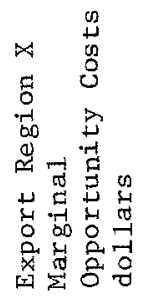

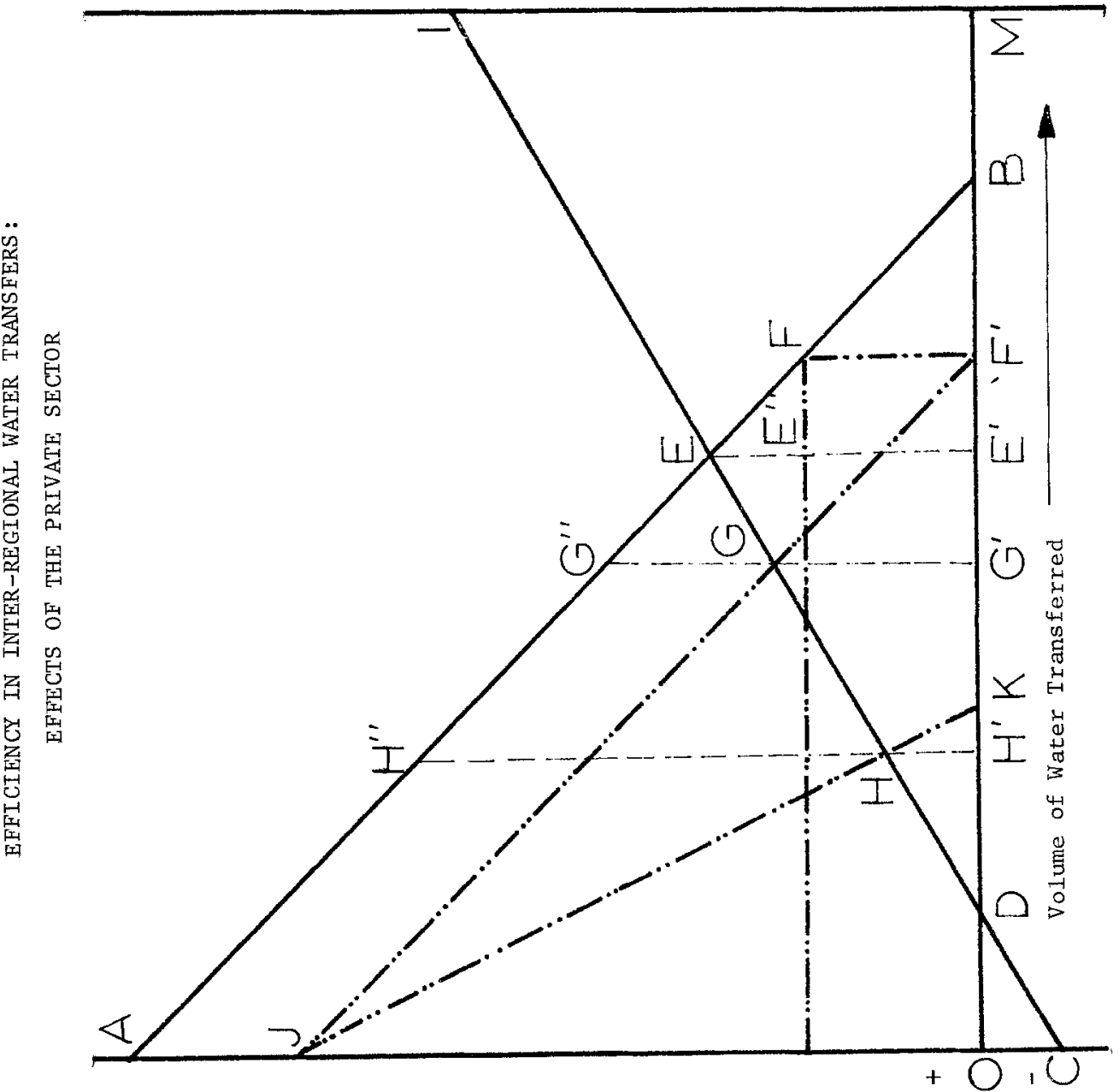

$p-1$

5
0
01
0

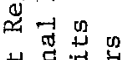

山亖占

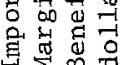

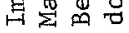


independently or collectively if their alternatives are investments outside the regional governments' jurisdictions. In this respect each region as the resource owner or importer has a legitimate self-interest in accounting for these benefits. 26

We have seen in figure 1 that without the added restriction of a minimum net return to private enterprises the most efficient point of water transfer is given at $\mathrm{E}^{\prime}$. At this point total social net benefits of the last unit of water purchased by $\mathrm{Y}$ is equal to total social net benefits given up by $\mathrm{X}$. To simplify the analysis, let us first assume that no private water rights impede region $X^{\prime}$ 's export water allocation decisions. 27 Let us further assume that all units of water which could be transferred to $Y$ require private activities for utilization. $\mathrm{Y}$, therefore, in order to utilize the last unit of water at $\mathrm{E}^{\prime}$ must attract a private activity which requires a minimum net return of E'E". Total net return to $Y$ is $E^{\prime} E$. $Y$, then, can tax or charge the private activity in the amount of EE" leaving $E^{\prime \prime} E^{\prime}$ as the minimum return to the private sector. But $X$, in giving up the marginal unit of water at $\mathrm{E}^{\dagger}$, gives up a net return of $\mathrm{EE}^{\prime}$ and, being rational, will require at least that much in compensation from $\mathrm{Y}$. $\mathrm{Y}$, having only $E E^{\prime \prime}$ at its disposal, is unable to pay $X^{\prime}$ 's reservation price out of its water revenues. $E E^{\prime}$ which in terms of inter-regional efficiency is the optimal point of water transfer may no longer be chosen.

It would be argued, of course, that $Y$ should pay the full reservation price of $\mathrm{X}$ at point $\mathrm{E}^{\prime}$ and, by doing so, subsidize its private sector (or the firm using the water respectively). But this would require higher taxation in $Y$ which, in effect, would represent an income transfer from the general taxpayer in $\mathrm{Y}$ to the specific private firms or individuals utilizing the water. To the extent that higher taxation levels would be required welfare of private taxpayers in $\mathrm{Y}$ would be reduced. The opportunity costs of higher taxation may be substantial and could well be much in excess of the private net benefits represented by E' $E^{\prime \prime} .28$ Only if all these costs are fully accounted for and if, in addition, the resulting equity issues between general taxpayers and water users are resolved could the rationale of subsidizing these private activities be decided upon.

Only beyond point $\mathrm{G}$ (in the direction of $\mathrm{O}$ ) will $\mathrm{Y}$ be able to compensate $X$ out of revenues resulting from the water transfer since at $G^{\prime}$ the remaining appropriable net benefit available to $Y$ is equal to $G^{\prime}$, the reservation price

26 The same reasoning applies, for example, vis a vis the self-interests of the United States and Canada (to the extent that capital transfers are likely or possible between the two countries).

27 Alternatively, we could assume that $\mathrm{X}$ is able to buy-out or expropriate such private waterrights at their marg inal values as given by function $\mathrm{DD}$.

${ }^{28}$ This could very easily be the case if the water-using activity is of a lowvalue type such as forage or grain-crop irrigation agriculture, and if the marginal opportunity cost of additional taxes in region $\mathrm{Y}$ is high. 
of $\mathrm{X}$ at this point. ${ }^{29}$ The equilibrium trading position resulting from the minimum profit demands of the private sectors in $X$ and $Y$ will now be given by point $G^{\prime}$. Total inter-regional net benefits, which previously were given by area CAE now are reduced to CAG"G. The net loss to society as a whole will be GG"E.

Even greater inefficiencies are likely to result if the importing region's government is forced to charge a uniform price for imported water to all of its customers, ${ }^{30}$ and if it insists further on maximizing its net revenue from its water import activity. 31 In this case the average net revenue function facing $\mathrm{Y}$ is given by $\mathrm{JGF}^{\prime}$ and its marginal net revenue function by JHK. Net governmental revenues are maximized at point $\mathrm{H}$ which means that under such a policy the amount of water imported is going to be no greater than OH'. 32

Inter-regional inefficiency, therefore, is likely to be one of the results of regional ownership of resources. A fully developed system of compensation payments will help to reduce these inefficiencies but is unlikely to eliminate them entirely.

${ }^{29}$ In Figure 2 the construction line $\mathrm{JF}^{\prime}$ which is parallel to $\mathrm{AB}$, has been drawn in such a way that $\mathrm{JA}$ is equal to $\mathrm{JO}=\mathrm{FF}$ '. Hence $\mathrm{G}^{\prime} \mathrm{G}$ is equal to the minimum private profit expectation $\mathrm{JO}=\mathrm{FF}^{\prime}$.

30

This is not an unreasonable assumption although several levels of water prices to different classes of customers may be a more realistic one. However, to include the latter would only complicate the argument without changing the general validity of the conclusion.

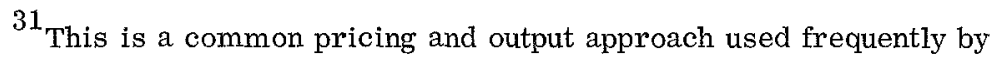
government-owned utility operations.

${ }^{32}$ Discriminatory pricing policies to different classes of users and the common practices to grant quantity discounts to large consumers in each user class moves the marginal revenue curve JK further to the right, however. 